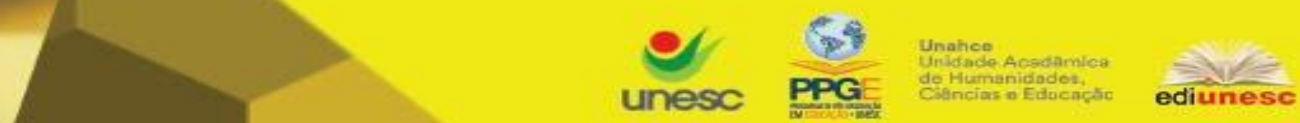

Criar Educação, Criciúma, v. 8, no2, ago/dez 2019.- PPGE - UNESC - ISSN 2317-2452

\section{DA HISTÓRIA DE UMA CULTURA A UMA PRÁTICA DE PESQUISA: NOTAS SOBRE CINEFILIA E EDUCAÇÃO}

\author{
Sandra Espinosa Almansa ${ }^{1}$
}

\begin{abstract}
RESUMO
Em diálogo com os estudos éticos de Michel Foucault, este texto trata de problematizar, sob uma dada conjuntura, a experimentação cinematográfica em relação a uma atividade a qual, para além do exercício cinéfilo de tomada de atitude com o cinema por si só, possa ser pensada como impulsionadora de um exercício do sujeito para consigo mesmo. A diagonal traçada da cinefilia nessa direção é tensionada por meio dos últimos estudos de Foucault especialmente na órbita das relações entre sujeito, verdade e práticas de si: de onde se recolhe elementos para discutir, diante do gesto e da composição de práticas concretas e da experiência narrada por "amantes do cinema" (dentre os quais figuram homens e mulheres de diferentes idades e formação variada) sobre as possibilidades de constituição ética e estética, então ocasionadas.
\end{abstract}

Palavras-chave: Cinefilia. Experiência do cinema. Exercício consigo. Formação.

\section{FROM HISTORY OF A CULTURE TO A RESEARCH PRACTICE: NOTES ABOUT CINEPHILIA AND EDUCATION}

\begin{abstract}
In dialogue with Michel Foucault's ethical studies, this paper problematizes the cinematographic experimentation in relation to an activity which, for beyond the cinephile exercise of adopting an attitude towards the cinema itself, can be thought of as a booster to an exercise of the subject towards himself. The diagonal drawn from the cinephilia in this direction is tensioned through the last Foucault's studies especially in the sphere of relations between subject, truth and practices of the self, from where it collects elements to discuss, in face of the gesture and the composition of concrete practices and the experience narrated by "movie lovers" (among which are included men and women of different ages and from diverse educational backgrounds), on the possibilities of the ethical and aesthetic constitution then occasioned.
\end{abstract}

Keywords: Cinephilia. Cinema experience. Actions exercised on the self by the self. Formation.

\footnotetext{
1 Licenciada em Filosofia pela Universidade Federal de Pelotas. Doutoranda em Educação pela Universidade Federal do Rio Grande do Sul. Endereço eletrônico: sandraealmansa@gmail.com NOTA: Este texto, com as devidas adaptações, foi apresentado no 6으 Seminário Brasileiro de Estudos Culturais e Educação, na ULBRA/Canoas, realizado de 01 a 03 de junho de 2015.
} 
Tudo ao mesmo tempo: essencialmente moderno, distintamente acessível, poético e misterioso e erótico e moral - eis o cinema (SONTAG, 1996). Uma arte que, à semelhança de outras artes, provoca sensações, emociona, faz pensar, inspira amores. Trata-se, no entanto, de um amor especial. Evidentemente não no sentido de uma excelência aos demais, senão no que diz respeito, isso sim, aos modos pelos quais se constitui e de outros se distingue.

A cinefilia, à qual o termo designa como uma forte afeição, um grande interesse, entusiasmo, ou, simplesmente, como amor ao cinema, foi o território do qual partimos para realizar a pesquisa da qual este texto se origina. E dizemos território não por acaso, mas por se tratar, justamente, de um terreno expressivo estreitamente relacionado ao domínio da subjetivação, a qualidades sensíveis e a valorações de ordem existencial. Além do mais, estamos falando de um terreno de práticas culturais, de uma cultura que engendra modos e ritos de olhar, de fala, de escrita (DE BAECQUE, 2010).

Não obstante, uma inquietação quanto à definição da noção de cinefilia ganha força em nossos dias. Em parte por conta de certo desvanecimento de seus contornos de outrora, quando a experiência do cinema se associava, à risca, à experiência da sala escura. Desde sua origem, a cinefilia se viu atrelada a uma concepção canônica do cinema. Logo, abordá-la hoje implica atenção às transformações pelas quais passa o hábito de ver filmes: como pensá-la, atualmente, senão sob a égide de sua variação e descontinuidade? O devir histórico e cultural da arte cinematográfica, o qual transforma inclusive, e sem hesitação, suas formas de recepção de acordo com outros dispositivos de presença do cinema para o espectador (DUBOIS, 2013), afeta, sem dúvida, o exercício da cultura cinéfila e o pensamento a seu respeito.

Por um lado, o termo cinefilia carrega consigo matizes de dogma e ritual específicos, mediante os quais se constroem práticas e discursos que visam legitimar culturalmente o cinema, seus autores e gêneros. Por outro lado, ele se refere de modo amplo à qualificação amorosa da relação com o cinema - visto o valor especial atribuído à experimentação cinematográfica e à vida que circunda os filmes. Sob esse olhar amoroso, sabemos, o gosto pelo cinema se imbuiu de uma qualidade inventiva, de uma espécie de força criadora, sendo seu apogeu observado com os movimentos da comunidade cinéfila na França, por entre os anos de 1944 a 1968. Nesse período a cinefilia inaugura, mais do que nunca, a invenção de um olhar; e dá ensejo, concretamente, a história de uma cultura (BAECQUE, 2010). É possível dizer que a 
invenção desse olhar, com a qual se desenha não apenas a história cultural da cinefilia, mas do próprio cinema moderno, diz respeito a uma aprendizagem. Aprender a ver, com os filmes vistos, amados, discutidos, foi motriz para a criação de novos olhares, para a criação de novos modos de fazer filmes e de apreciá-los; em suma, de se relacionar e operar com imagens cinematográficas. Aprender a ver torna-se então, com o cinema, criar o ver (BAECQUE, 2010, p.54, grifos do autor).

Ora, se é possível assegurar que, ainda hoje, um sem número de pessoas continua a ser capturado e fascinado pela magia das imagens do cinema, seguro também é o fato de que isto se dá diferentemente de outrora, passado quase meio século da "idade de ouro" da cinefilia. Mantém-se, por certo, a valorização de momentos pessoais de descoberta e alegrias com o cinema, desenvolvem-se também rituais afetivos, bem como se continua a celebrar seu amor em comunidades especializadas (VALK; HAGGENER, 2005). Mas as condições de possibilidade para tanto se ampliaram com o advento de novas tecnologias de produção e reprodução audiovisual, e, em geral, das variadas tecnologias de informação e comunicação. A partir dos anos de 1950 fomos, aos poucos, nos habituando a ver cinema pela televisão, e após disso, através de diversas máquinas que passaram a fazer parte de nosso cotidiano (DUBOIS, 2013). Às vezes assistimos a filmes on-line, às vezes ao ar livre, em mostras e festivais.

Enfim, diante de tantas transformações, das quais não é propósito, por ora, nos ocuparmos, seria preciso deixar em suspenso, em alguma medida, as circunstâncias de metamorfose da cinefilia e dela guardar um debrum de memória. Sob este a tomamos não apenas como uma forma própria de recepção, mas, especialmente, como uma prática inscrita na cultura de nosso tempo, e da qual consideramos alguns desdobramentos e possibilidades à criação de uma interface de pesquisa na educação (BAECQUE, 2010).

\section{Da paixão à pesquisa, o aporte de um método}

Inscrita no rol dos estudos que têm como tema as relações entre os meios de comunicação e os processos de subjetivação na cultura (FISCHER, 2012), a pesquisa cujo recorte nós aqui exploramos empreendeu investigar e descrever o papel desempenhado pela experimentação cinematográfica sobre sujeitos que mantém, com o cinema, relações tais que possam ser consideradas práticas - contínuas e, em 
certa medida, regradas. Se a frequência em salas de cinema constitui parte desse conjunto de práticas, ela não se exibe consensualmente como de maior importância do que a participação em cineclubes para assistir e discutir filmes; ou mesmo do que a prática de baixar e colecionar obras partilhadas em sites da internet, lugar em que também se debate coletivamente os filmes, e suas impressões sobre eles. Entrevistamos sujeitos que leem sobre cinema e escrevem sobre filmes com diferentes intenções, que propõem coisas com eles de diferentes formas, que constroem seus próprios arquivos de imagens cinematográficas, e de algum modo, as animam. De resto, é preciso dizer que nossa interlocução se realizou com pessoas que mantêm com o cinema certo vínculo, uma relação ativa, dinâmica, motriz passível de ser qualificada como uma relação amorosa, mas, sobretudo, distinta como uma prática cultural, social e discursiva. Nosso corpus empírico constituiu-se de depoimentos acerca da experiência do cinema e do que nela acontece. No total foram realizadas doze entrevistas, a mulheres e homens entre 21 e 54 anos de idade. De modo particular, cada depoimento lançou à superfície pontos de vista, efeitos de sentido, considerações, perspectivas e valorações sobre a prática de ver filmes e suas práticas extensíveis. Cada participante pode falar sobre como se constitui concretamente sua relação com cinema: com que frequência assiste a filmes, sob quais condições, em quais contextos se insere como espectador, etc. Por outro lado, a experiência do cinema foi também abordada a partir da emergência de memórias, sensações, perspectivas e efeitos aí produzidos. Propôs-se a rememoração da história da relação com o cinema através da evocação de imagens e filmes, dos quais cada participante guarda a lembrança, a emoção ou a percepção (DELEUZE, 1985). Diante disso, nosso propósito residiu em problematizar e analisar os modos pelos quais, nas práticas descritas por um grupo de cinéfilos, incide não apenas a constituição do saber sobre cinema, mas do próprio sujeito que com ele se ocupa.

Dado nosso objetivo, o exercício de nossas perguntas não poderia ter sido realizado, a rigor, sem uma espécie de saída da cinefilia em direção à educação, campo sobre o qual incorre, junto às relações com o cinema, nosso interesse. Em especial, no que diz respeito aos efeitos da arte cinematográfica sobre os sujeitos, sobre seu pensamento, seu olhar e suas vidas. Deste modo, a pergunta sobre para que a cinefilia serviria ao pensamento sobre cinema e educação foi substituída pela indagação acerca de como algumas práticas com o cinema são constituídas, e de que 
modos o que nelas acontece pode nos oferecer elementos para pensar a dinâmica dessas práticas na formação de pessoas.

Assim, ainda que possa ser considerada como maneira de assistir os filmes, deles falar ou difundir um discurso; ou que possa ser descrita como uma vida que se organiza em torno dos filmes (BAECQUE, 2010), nós deslocamos a cinefilia das definições a um problema, composto com a pergunta a respeito dos modos pelos quais, nas práticas que essa cultura abarca, se produzem olhares, sensações e pensamento capazes de mobilizar nosso ser mesmo de sujeitos. Dito de outra maneira, perguntamos sobre o que estaria acontecendo na experimentação cinematográfica de alguns amantes do cinema, para discutir sobre a relação entre cinema e educação no sentido de sua dimensão formativa, na qual se apresentam e dinamizam valorações, visões de mundo, conhecimentos, etc. Em vista disso, as práticas narradas foram tensionadas em relação a uma atividade a qual, para além do exercício cinéfilo de tomada de atitude com o cinema por si só, pudesse ser pensada como impulsionadora de uma atitude do sujeito para consigo mesmo (FOUCAULT, 2010), um movimento de labor de si por si mesmo com (a) e a partir da experimentação cinematográfica.

Nesse contexto espreitamos a agência de processos de subjetivação formativos e transformativos, e nessa perspectiva mobilizamos, então, o conceito de educação. Talvez seja preciso elucidar, ainda outra vez, nossa filiação ao acordo de que não é apenas a escola que educa. Sabemos, evidentemente, que práticas e relações educativas acontecem e se efetivam em diferentes tempos e em espaços distintos em nosso cotidiano. Assim que educação "não se limita mais a ser um sinônimo de escola", já que "diversas instâncias da cultura hoje se ocupam, das mais diferentes formas, em produzir, em formar, enfim, em educar sujeitos" (MARCELLO; FISCHER, 2011, p. 506, grifo das autoras). Longe disso, desvalorizar o papel da escola: o que reconhecemos e apostamos, sim, é que essa diversidade amplia, por outro lado, nossos modos de pesquisar em educação - os quais se modificam, e tornam-se cada vez mais complexos (MARCELLO; FISCHER, 2011).

Metodologicamente operamos, em diagonal, com o conceito de práticas de si junto ao qual Foucault buscou descrever e analisar, por meio de textos de filósofos antigos, a constituição do sujeito na Antiguidade clássica greco-romana, evidentemente direcionando-o às nossas inquietações e ao tempo presente. Ou seja, propusemos, a partir de alguns elementos que os estudos éticos de Foucault nos 
oferecem, pensar as relações com o cinema em direção à órbita das práticas refletidas da liberdade. Nosso objeto de estudo foi construído de modo a abranger, através do diálogo com o grupo selecionado para a ação investigativa, tanto a complexidade das linguagens específicas com que se faz cinema quanto interrogações de ordem filosófica, histórica, cultural, estética e pedagógica (MARCELLO; FISCHER, 2011, p. 506). No texto a seguir, apresentamos uma pequena parte da pesquisa e de suas análises. Nele, as passagens em negrito trazem excertos dos depoimentos recolhidos.

\section{Cenas íntimas e outras: um breve olhar sobre as narrativas}

As palavras a respeito de suas histórias com o cinema fazem ver que, para a maioria dos entrevistados, o cinema se abeira à vida logo cedo. Essa referência ao passado, no entanto, não busca enaltecer uma ideia de progresso em fases da vida, ou de desenvolvimento ideal e integral do indivíduo, nesse sentido. Pelo contrário, seria preciso substituir a repartição da vida em fases por uma espécie de unidade dinâmica, pois o que importa é justamente dedicar atenção à dimensão da memória, na medida em que se entende que como memória nós somos construídos: que "somos a um só tempo a infância, a adolescência, a velhice e a maturidade" (FELLINI apud DELEUZE, op. cit. 2009).

Embora o interesse varie, diferindo nas passagens da infância para a adolescência e desta para a vida adulta, ele ganha força, transforma-se e se amplia com o passar do tempo. Dos 12 participantes, 8 mencionaram ter começado a se interessar pelo cinema na infância e 3 narrativas não explicitam esse dado, embora tragam em comum as considerações: sempre gostei muito de assistir a filmes e mantenho o interesse pelo cinema desde sempre. Uma última considera que, metodicamente, a prática de ver filmes se iniciara aos dezesseis anos. Diz-se que a cada época de nossas vidas, no entanto, é possível eleger um filme significativo.

Ao longo de sua narrativa, um dos depoentes deu destaque a um filme que, segundo ele, Ihe retornava insistentemente à memória, depois de tanto tempo. Tratase de Caro Diário (Nanni Moretti, 1993)². Segundo ele um filme simples, feito com

\footnotetext{
2 "Caro Diário, existe uma coisa que eu gosto mais que tudo": com essa frase, o diretor Nanni Moretti inicia o filme. Vemos uma imagem silenciosa, onde em um primeiro plano fixo uma mão segura uma caneta que desliza sobre a folha de um caderno, nela escrevendo. Trata-se de um exercício solitário e silencioso, como não poderia deixar de ser: trata-se da escrita de um diário íntimo. A diferença é que
} 
imagens do dia-a-dia, um filme "caseiro", mas ao mesmo tempo desconcertante, em que tudo leva a crer que foi feito "sem querer", feito para não impressionar. Um filme que teria tudo para ser tedioso: afinal, qual a importância em olhar o cotidiano de um homem em sua tentativa de realizar um filme? Pois foi precisamente este o motivo de seu primeiro impacto sobre o espectador, por se tratar de um filme diferente do que estava acostumado, mas que the despertara um enorme interesse: pela vida do personagem, pela maneira como ele encara o mundo, e também um interesse pelo cinema, interesse em levar a vida como arte, a tal ponto de ser transformada num filme. Difícil explicar, ele conclui. Só vendo pra entender.

A respeito da experimentação do cinema na infância, destacamos as falas a seguir, as quais nos foram dadas como resposta à pergunta a respeito do interesse pelo cinema, se recente, ou se mantido há algum tempo. Acho que me apaixonei pelo cinema com uns 5 anos, quando assisti Jurassic Park (Steven Spielberg, 1993) no cinema, com meu pai. Lembro que achei aquilo o máximo, eram dinossauros de verdade! Eles me assustavam, mas ao mesmo tempo eu queria estar ali. Meu pai alugava todos [os filmes d'Os Trapalhões]. O que me atraía - e, claro, eu não sabia o nome - era a mise-em-scène: a vida da cena, sua grafia, seu movimento, seu instante, - como era possível tudo aquilo? Indiana Jones (Steven Spielberg) ${ }^{3}$ e a trilogia Guerra nas Estrelas (George Lucas, 1997; Irvin Kershner, 1980; Richard Marquand, 1983) supriam minha imaginação com conteúdo para brincadeiras, em grupo ou solitárias, repletas de espadas laser, chicotes e pistolas. Eu atuava e recontava para mim mesmo as estórias dos filmes, assumindo o papel de protagonista.

Ao longo dos depoimentos a experiência do cinema é valorada como uma experiência do olhar, do saber ver, do tentar ver mais; uma experiência que toca a alma; que faz despertar a visão sobre as coisas; que possibilita a imersão em outras realidades; e faz desenvolver certas habilidades de olhar o mundo. Vê-se quão manifesta é a menção aos efeitos óticos da experimentação cinematográfica, os quais envolvem uma espécie de deslocamento de nós mesmos, um movimento imanente de nossos eixos de visão, de nossos olhares sobre aquilo que vemos. Um movimento pode-se dizer, de ir e vir sobre as imagens, no qual talvez alguma coisa [aconteça]

Moretti nos convida a partilhar, com seu filme em "três capítulos", do fora que o leva a tal escrita: ao se deslocar sobre diferentes lugares e situações, o cineasta-protagonista põe em cena as travessias com que se compõe uma biografia, no caso, a sua, e nos convida, sob um misto de comicidade e tragédia, a pensar sobre os movimentos dentre os quais nos tornamos quem somos.

${ }^{3} \mathrm{O}$ depoimento não especifica ou se remete diretamente a qualquer dos quatro filmes da série. 
com o sujeito que assiste a um filme, como afirma um dos entrevistados. Em meio a tal agitação cada qual olha também a si mesmo, olhar este que não é pura interioridade, mas um movimento que nos leva para fora de nós, como experiência, e nos transforma (FISCHER, 2012). Subjetivamente, conta-nos uma depoente, sei que aprendo muitas coisas, do mundo e da natureza humana.

Andrei Tarkovski é mencionado como realizador de um cinema com uma força muito grande para deslocar o espectador até um ponto em que ele não se reconhece mais. De outro modo, diz-se que os filmes de Lars Von Trier criam processos de identificação muito fortes e depois deslocam os personagens de maneira agressiva, arrastando o espectador a esse ponto de estranhamento de si. Desse último são citados os exemplos de Dançando no Escuro (Lars Von Trier, 2000), no qual quase sentimos a dor e o sofrimento da personagem da Bjork (Selma Jezkova, protagonista do filme), e de Dogville (Lars Von Trier, 2003), em que nos condoemos com a personagem principal ao ponto de apoiarmos toda e qualquer vingança possível contra seus algozes. E eis que então a personagem, a qual por empatia obtém todo nosso assentimento enquanto espectadores leva a vingança até um ponto em que nunca seríamos capazes de admitir, e o espectador fica se perguntando: eu estou mesmo de acordo? Era essa vingança que eu buscava?

Além de destacar o prosseguimento, pós-sessão, de debates e diálogos abertos a respeito da experiência fílmica, os depoimentos mostram que se segue à prática de ver filmes a ação de escrever sobre eles, sobre as impressões e sensações por eles provocadas - a partir e junto delas. Pode-se dizer que a relação é uma das características dessa escrita, na qual os olhares passam então a se dirigir a outros que não mais somente os filmes: escreve-se para outros, escreve-se para acessar tal ou tal obra, e o pensamento de tal ou tal cineasta. Não se trata, com isso, de convencer o outro, mas de [uma] tentativa de criar caminhos, aberturas, frestas mesmo por entre os filmes. Este é um dos motivos pelos quais se valora a experiência do outro [como] tão importante para o cinema. Sem ela, diz-se, ele talvez não existisse de todo.

Escreve-se para ampliar o olhar com o que foi visto, para acessar o pensamento da obra e para criar aberturas por entre os filmes. Escreve-se de sua experimentação fílmica a outro e deste se recebe a sua, oferece-se aquilo que se pensa, percebe e sente a um olhar possível. Escrever sobre os filmes é, portanto, uma prática que se cultiva, à qual os depoimentos atribuem valor significativo. Um dos entrevistados, do 
qual a escrita se relaciona a atividades como curadoria de cineclubes, a blogs pessoais e coletivos que mantém sobre cinema, entre outros, refere-se a essa prática como uma busca por aquilo que viveu. Para outro depoente, escrever sobre cinema é uma extensão da própria experiência do filme, pois, subjetivamente, o bom filme não termina após os créditos. Ele fica com você, exige pensamento e esforço crítico. Além disso, a escrita também funciona como registro das imagens que se vê - e são muitas - para além da durabilidade delas na tela.

\section{Educação e cinema: entre imagens, olhares e efeitos}

A afirmação de que as imagens não duram apenas na tela nos conduziu, e tem nos conduzido, desde então, à pergunta a respeito de onde mais elas duram, e de seus efeitos educacionais. Aí se encontra, talvez, uma das interrogações mais inquietantes às quais deu lugar a pesquisa. Seu desenvolvimento, por sua vez, legitima sem reservas a proposição de que "pesquisar o cinema na educação tem a ver com a educação do olhar", de um olhar que "se ocupa de modos de olhar o mundo, as pessoas, os grupos sociais, a história presente" (MARCELLO; FISCHER, 2011, p. 507). A dimensão educativa apresentada em cada narrativa compreende uma formação mobilizada como processo, em que se dinamizam, dentre outros, nossos valores, nossa visão de mundo, nosso pensamento e nossas escolhas, nosso conhecimento sobre nós mesmos, sobre os outros e sobre a vida. Nesse processo de formar-se e se transformar com e através da experiência do cinema e das práticas que desdobra, a relação consigo mesmo se dá, como observamos, em vista de outros, os quais se tornam presentes, justamente, em meio às relações com essa arte.

As imagens e narrativas do cinema, ao não se esgotarem na tela e tampouco no fim do filme quando, muitas vezes, dão lugar aos créditos da obra, não apenas convocam nossos olhares como duram em nós, em nossas escritas, nos registros que fazemos; em nosso próprio corpo, na vida que dura em nós, expondo a importantes aprendizagens que mobilizam, ética e esteticamente, nosso si mesmo. Diante das narrativas, das quais aqui exploramos apenas um pequeno recorte, perguntamos sobre os modos pelos quais a reminiscência destas ou daquelas imagens, histórias, planos, personagens e situações que vemos nos filmes, com as quais experimentamos nosso pensamento e sensações de modo diferente, 
constituem algo do que somos, a partir de alguns elementos que o pensamento de Foucault (2010) nos oferece, e da perspectiva de Badiou (2004), a respeito do cinema como experimentação filosófica.

Nesse sentido um elemento, presente na maioria dos depoimentos, foi da maior importância para a análise: o outro. Em alguma medida, o outro se mostra fundamental na mobilização das forças de imaginar, de recordar, de conceber, de querer, etc. (DELEUZE, 2011), assim como se faz indispensável na constituição das práticas narradas, e na experiência mesma do cinema. Nas práticas descritas por Foucault (2010), vemos que a importância do outro era absolutamente necessária àquele que pretendesse cuidar de si mesmo, ocupar-se consigo. Era um princípio, geralmente admitido, aquele que dizia que isso não seria possível sem a sua ajuda.

Outro, igualmente, imprescindível à ação de escrever: atividade por meio da qual talvez seja também possível pensar o impensado, mas ainda de captar o já dito (FOUCAULT, 2004), de construir um logos para si mesmo com esse e com a experimentação cinematográfica, a partir e por meio dela. Escrever para si e para outro desempenhou um papel considerável, por muito tempo, na história do cuidado de si (FOUCAULT, 2004). Constituía uma prática ascética, um treino de si por si mesmo, o qual, entre outras formas, comportava memorizações, meditações, silêncio, escuta do outro. As práticas envolvidas no cuidado de si constituem um fenômeno extremamente importante na história das práticas de subjetividade. $\mathrm{O}$ legado desse tema, certamente, é bastante rico, e muito embora as práticas analisadas por Foucault digam respeito a um tempo e contexto específicos, sua história e desenvolvimento não se esgotam naquele período. Das tecnologias de si, domínio bastante amplo, e sobre o qual há que se fazer a história (FISCHER, 2012), deve-se reter que são aprendidas, vividas sempre na relação com o outro, relação a qual envolve trabalho sobre o corpo e a alma e, ao mesmo tempo não separa logos e ação (FISCHER, 2009).

Badiou (2004), para quem o cinema mantém relações muito particulares com a filosofia, sugere que se trata de uma relação viva, concreta; de uma relação, podese dizer, de transformação. O próprio cinema é, para o filósofo, uma situação filosófica, justamente por ser uma a arte que nos incita a pensar na vida e em suas transformações na medida em que nos coloca diante de situações filosóficas que nos exigem uma decisão do pensamento frente ao que acontece; frente ao que se mostra quando o que se mostra é heterogêneo, estrangeiro, outro. Tanto é assim 
que, em sua perspectiva, o cinema é tratado como um novo pensamento do outro, como uma nova maneira de fazê-lo existir. Ao apresentar o outro no mundo, em sua própria intimidade e em sua relação com o espaço, o cinema nos conduz a pensá-lo e a com ele pensar ao mesmo tempo em que torna essa capacidade ampliada, pois que o exige (ao outro).

Em sua maioria, as narrativas com as quais trabalhamos nos dão a ver sujeitosespectadores postos diante de relações entre termos de natureza distinta, dispostos a relações as quais, menos do que confortar seu olhares e pensamento, vertem paradoxos que os forçam a pensar sobre o que veem. A atenção de Badiou (2004) à presença de relações paradoxais no cinema, relações compostas de termos heterogêneos que nos exigem participação por meio da eleição de olhares ou "pontos de vista", mostrou-se bastante relevante para pensarmos a potencialidade educativa do cinema ao lado do conceito de práticas de si. Em parte à vista do amplo alcance ético-político do cinema, no qual se fazem presentes e entremeadas tanto as opiniões ordinárias quanto o trabalho do pensamento. De acordo com o Badiou (2004, p. 34), esse alcance se dá por ser o cinema uma

[...] arte das figuras, não somente das figuras do espaço, no só das figuras do mundo exterior, senão das grandes figuras da humanidade em ação [...]. São formas fortes, encarnadas, dos grandes valores que se discutem em um momento dado. [...] Há um aspecto admirável em tudo isto, admirável como poderia ser a tragédia grega: propor a um imenso público figuras típicas, grandes conflitos da vida humana.

O que se põe em jogo, ou melhor, em cena, são sim grandes conflitos da vida humana. De modos distintos, seja sob a "forma do grande horizonte" - em que o conflito é dilatado, amplificado em um espaço mais vasto para se tornar visível, e no qual símbolos amplificadores o instauram estendendo-o para além do ordinário; ou do "espaço fechado" ou ainda "pequeno grupo" - em que o conflito é encerrado em um pequeno espaço no qual cada parte de um pequeno grupo mostra um valor e posição (BADIOU, 2004); ele nos aponta, de modo inegavelmente amplo, um comum de nossa humanidade, atravessado, precisamente, pela diferença.

É possível concluir que, dos laços estabelecidos com o cinema nas práticas descritas, a experimentação fílmica é valorada em face de circunstâncias as quais interseccionam: a) a atualização de multiplicidades sociais que nos afetam (FUGANTI, 
2012) b) processos de subjetivação nos quais se evidencia uma dimensão vitalista da experiência; c) um retorno do olhar e do pensamento sobre si mesmo, a partir de imagens, personagens, cenários e situações vistas na tela.

\section{Referências}

BADIOU, Alain. El cine como experimentación filosófica. In: YOEL, Gerardo (Comp.). Pensar el cine 1. Imagen, ética y filosofia. Buenos Aires: Manantial, 2004, p. 23-81.

BAECQUE, Antoine. Cinefilia: invenção de um olhar, história de uma cultura, 19441968. São Paulo: Cosac Naify, 2010.

DE VALCK, Marijke; HAGENER, Malte (Orgs.). Cinephilia: Movies, Love and Memory. Amsterdam: Amsterdam University Press, 2005.

DELEUZE, Gilles. A imagem-movimento (Cinema I). São Paulo: Brasiliense, 1985.

. A imagem-tempo (Cinema II). São Paulo: Brasiliense, 2009.

. Foucault. São Paulo: Brasiliense, 2011.

DUBOIS, Philippe. Aula Magna do Curso de Cinema da Universidade Federal de Santa Catarina em 02 de Abril de 2013. Disponível em https://www.youtube.com/watch?v=bq8nYh6DWhA\&list=LL1oFT-

A9Q2zsBdz5iBM2s9w Acessado em abril de 2015.

FISCHER, Rosa Maria Bueno. Docência, cinema e televisão: questões sobre formação ética e estética. In: Revista Educação e Realidade. Vol.14, n.40, 2009, p. 93-102.

Trabalhar com Foucault: arqueologia de uma paixão. Belo Horizonte: Autêntica Editora, 2012.

FOUCAULT, Michel. A escrita de si. In. Ética, Sexualidade, Política (Ditos e escritos V). Rio de Janeiro: Forense Universitária, 2004, p. 144-162.

A hermenêutica do sujeito: curso dado no Collège de France (1981-1982). São Paulo: Ed. WMF Martins Fontes, 2010.

FUGANTI, Luiz. Ética como potência e moral como servidão. Disponível em http://escolanomade.org/pensadores-textos-e-videos/fuganti-luiz/etica-comopotencia-e-moral-como-servidao Acessado em abril de 2015.

MARCELLO, Fabiana de Amorim; FISCHER, Rosa Maria Bueno. Tópicos para pensar a pesquisa em Cinema e Educação. In: Revista Educação e Realidade v.36, n.2, 2011, p. 505-519. 
SONTAG, Susan. The decay of cinema. The New York Times, 1996. Disponível em https://www.nytimes.com/books/00/03/12/specials/sontag-cinema.html Acessado em Abril de 2014.

\section{Filmes citados}

SPIELBERG, Steven. Parque dos Dinossauros [Jurassic Park]. EUA, 127 min., 1993.

KERSHNER, Irvin. Guerra nas Estrelas - O Império Contra-ataca [Star Wars - The Empire Strikes Back]. EUA, 124 min., 1980.

LUCAS, George. Guerra nas Estrelas - Uma Nova Esperança [Star Wars - A New Hope]. EUA, 121 min., 1977.

MARQUAND, Richard. Guerra nas Estrelas - O Retorno de Jedi [Star Wars - Return of the Jedi]. EUA, 134 min., 1983.

MORETTI, Nanni. Caro Diário. Itália/França, 100 min., 1993.

VON TRIER, Lars. Dançando no escuro [Dancer in the Dark]. Dinamarca [et al.], 140 $\min ., 2000$. . Dogville. Dinamarca [et al.], 178 min., 2003.

Recebido 23 de setembro de 2018.

Aprovado em 12 de maio de 2019. 